\title{
A Study on Operation Strategies of Unclogging Container-Trailers Enterprises at Shenzhen Port
}

\author{
Xiaoliang Gao and Nie Dan \\ Dept. of Logistics Management and Industrial Engineering, East China Jiaotong University, \\ Nanchang, P.R. China, 330013 \\ Gaoxiaoliangxin@163.com
}

\begin{abstract}
It is investigated that nearly $86 \%$ containers were transferred by roads connection transport at Shenzhen port with the high-speed developing steps of Chinese economy. For a long time, Shenzhen container-trailer enterprises have provided essential and efficient logistics service for every dock. However, problems as operated by many bodies, small scale, decentralized business and poor competitiveness, etc. was universally existed. Because the port, big international logistics enterprises, policies, environment, competitors, customers, insurance companies and maintenance companies have great affection on the cost and income of container-trailer enterprises, this paper conducts a comprehensive analysis on operating environment of these enterprises by using the dynamic game theory of incomplete information to study some useful running modes of high efficiency and low cost operation, and also some feasible measures have been proposed.
\end{abstract}

Keywords: Container transport, Shenzhen Port, SWOT Analysis, Gaming, Operation, Strategy.

\section{Preface}

In the world today, along with the global economic integrative development, leading by harbours served both as seaport and airport, relying on the logistics garden and top logistics industries as carrying bodies, modern logistics fulfilled a sustaining, rapid and sound development. A modern type of transport using containers as unit for cargo transportation was widely adopted increasingly. Container transport has many advantages as safety, environmental protection and punctually etc.

With the rapid growth of throughput of Shenzhen port in recent years, about $86 \%$ evacuation containers were transferred by road connection transport. Anyhow, the operation of road containers transport enterprises was not as good as people has expected. For external environment, as the lower threshold of market access on the one hand, the increasing of transportation capacity completely became enterprise or personal behavior. With the steadily increasing of enterprises and trailers and the oversupply of transportation, the market competition becomes fiercer. The head-on competition also lowers the freight rate while the continuously soaring of the price of oil, insurance expenses, tire, vehicle-use special oil and fittings, the running cost of 
logistics business remained high and the profits became small. On the other hand, under the influence of international financial crisis, resources stipulation and economic structure, etc., the import and export trade of the Zhujiang Delta was drop-off.

From business enterprise itself, many medium and small scaled roads container enterprises are poor at internal management with narrow business scope, simple profit model, low utilization of logistics information and poor combination of road transport and comprehensive logistics mode, the traditional road container transportation enterprises lacks core competencies on the opening logistics market.

\section{Overview of Road Container Transport Enterprises of Shenzhen City}

Compared with other port cities in China, the road connection transport ratio of Shenzhen port is the highest and the road container-trailers in Shenzhen is also the most.

The road container transport industry in Shenzhen was started in 1994. It has increased rapidly since its market was released in 1999. From 2005 to 2008, the capacity of road container transport increased continuously along with the increment of port throughput. The biggest increase was in 2007 and the trend became slowly since 2008.

\section{(1) Business model}

The road container transport industry has numerous business models, it can be divided into enterprise owned vehicles and non-enterprise owned vehicles. The business model of enterprise owned vehicles is mainly operated as self-support and cooperative operation (contractual leasing, a kind of non-employment relationship). The business model of non-enterprise owned vehicles is usually a kind of affiliated operation. Concretely, it is mainly divided into simple affiliation and business affiliation. The simple affiliation is operated at owner's expense, owners will pay certain amount of management fee to the enterprise and enterprise will pay all of tax and insurance fee for them together. The business affiliation is enterprise will manage business and financial affairs for owners and drivers.

\section{(2) Scope of business}

Three kinds of business are mainly conducted by logistics enterprises: General freight business, seaport subdividing business and airport subdividing business, including:

(1) Transporting sea-borne International containers from port to inland and related hand-over, storage, dismounting, clean and maintenance of containers, storage and distribution of cargo within inland transit station.

(2) Transporting local railway containers from station to consignor or consignee's warehouse, workshops and stock yards, cargo packing and unpacking agency.

(3) Transporting water transported containers along the coast or river to inland, transit transport and short distance door-to-door transport.

(4) Container direct transport through highway between cities.

(5) Container transport between Inland to Hong Kong, Macau and other frontier seaports, connection transport and mainland bridge transport. 


\section{SWOT Analysis of Road Container Transport Enterprises of Shenzhen City}

SWOT analysis is synthesizing and summarising all internal and external environmental conditions to analyse advantage factors (strengths), weaknesses, opportunities and threats for the enterprises. On the basis of this, matches all opportunities and risks resulted from internal resource factors and external factors reasonably and effectively, makes out excellent strategies to seize external opportunities and avoid threats. Take a road container transport enterprises for example, the matrix of SWOT analysis is showed as follows:

Table 1. The matrix of SWOT analysis of a road container transport enterprise

\begin{tabular}{|c|c|}
\hline Advantage(S) & Weakness(W) \\
\hline $\begin{array}{l}\text { S1 Regional Advantage: } \\
\text { There are more than } 70 \text { international lines docked at this port } \\
\text { regularly, its service was over most main ports of counties and } \\
\text { regions of America, Europe, Mediterranean, Southeast Asia, } \\
\text { North Asia, Middle East, South Africa and Australia. } \\
\text { S2 Inland economic advantage: } \\
\text { with adequate cargo resources as near the biggest export } \\
\text { machining base of Zhujiang Delta. } \\
\text { S3 Transportation advantage: } \\
\text { Shenzhen has formed a multi-modal transport center as "one } \\
\text { zone, three axes" connecting the home abroad, also linking } \\
\text { the Zhujiang Delta. } \\
\text { S4 Policy and system advantage: } \\
\text { Logistics has already became the pillar industry of Shenzhen } \\
\text { City }\end{array}$ & $\begin{array}{l}\text { W1 Weak position } \\
\text { W2 obvious Low-end feature } \\
\text { W3 Bad resource structure } \\
\text { W4 Bad evacuation system, time for waiting if } \\
\text { too long. } \\
\text { W5 Increasing insurance fee, insured claim is } \\
\text { very difficult to settle. } \\
\text { W6 Low informationization degree and high } \\
\text { no-load ratio. } \\
\text { W7 Many hit-and-run drivers and always hide a } \\
\text { goose in ones sleeves. } \\
\text { W8 Lack of professional talent person }\end{array}$ \\
\hline Opportunities $(\mathrm{O})$ & Threaten $(\mathrm{T})$ \\
\hline $\begin{array}{l}\text { O1 Political environment: } \\
\text { Policy supports of the nation and local government. } \\
\text { O2 Economic environment: } \\
\text { Advantages of strong export-oriented economy of Zhujiang } \\
\text { Delta } \\
\text { O3 Social environment: } \\
\text { Concerns of Society. } \\
\text { O4 Technical environment: } \\
\text { The organization and operation of the logistics enterprises } \\
\text { was greatly changed by IT theories and its application. }\end{array}$ & $\begin{array}{l}\text { T1 Oversupply and low price } \\
\text { T2 Continuously increased oil price and } \\
\text { disordered markets. } \\
\text { T3 Mixed maintenance factories } \\
\text { T4 Lots of fake-licensed cars , unfair } \\
\text { competition } \\
\text { T5 Longer funds chain } \\
\text { T6 Threaten of foreign large logistics enterprises } \\
\text { T7 Intensifying service competition of cities } \\
\text { around } \\
\text { T8 Lacking and aging drivers. }\end{array}$ \\
\hline
\end{tabular}




\section{Gaming Analysis of Unclogging Trailer Enterprises}

Those involved in the operation gaming of unclogging trailer enterprises are mainly included served ports, maintenance enterprises and oil enterprises related with trailer enterprises, etc. An analysis of this kind of gaming is listed below:

\subsection{The Analysis of Cooperative Gaming between Trailer Enterprises}

At present, the scale of most trailer enterprises in Shenzhen is generally small, all faces the situation of port monopoly, and the competition between trailer enterprises is very fierce. There will be gaming where competition exists. There are two kinds of competition strategies of those enterprises: cooperative strategy and non-cooperative strategy. This formed four strategic combinations of trailer enterprises such as ((cooperation, cooperation), (cooperation, noncooperation), (noncooperation cooperation), (non- cooperation, noncooperation).

To maximize the profit, which kind of strategy will be adopted under some certain circumstance? The continuous analysis will make further analyse to above problems.

\subsection{The Gaming Analysis between Ports and Trailer Enterprises}

Under the situation of repeating gaming, no matter who have the advantageous position, manufacturer or supermarket or even it is a fine match, the final result will be (cooperation, cooperation), an equilibrium solution because both parties can adopt a tooth for a tooth strategy to protect themselves.

First of all, we have made it clear that repeating gaming appears under what circumstance, it is very important. If the number of supermarkets that a manufacturer of certain product can choose is numerous, the gaming will be only for once, static and the equilibrium result will be (non-cooperation, cooperation) because the manufacturer can continuously change to some new supermarkets. For the same reason, if the number of supermarkets that a manufacturer of certain product can choose is much, and the number of supermarkets that can sell such kind of product is few, the gaming will be also only for once, and the equilibrium result will be (cooperation, non-cooperation) because the supermarket can continuously choose some new manufacturers. Only when the manufacturers of certain product are less while supermarket can be chosen is also less, in other words, the manufacturers and supermarkets have the same opportunities to threat the other party, and all have to choose the other party as its cooperative partner in future, then their cooperation will be for many times and the gaming between them is repeated gaming.

\section{Study on Operation Strategy of Unclogging Container Trailer Enterprises}

\subsection{Cooperative Competition Strategy with their Profession}

(1) Form a strategic alliance to promote its business position

With global logistics chain becomes closer and closer gradually, the market economy is the model of gaming and win-win, competition exists in the same business. Not in this 
way, the business will be proved. However, the same business also has to depend on each other to exploit market together.

\section{(2) Quicken the industrial upgrading and optimization}

Relying on the supply chain manage, new technique application and information-based construction, carry out the function integration and service extending; to build a green logistics system, propose green transport construction. To develop product and package, waste recovery logistics to promote recycling and economizing the resources.

\section{(3) Developing integrative logistics}

The road container transport industry gained a scale benefit and logistics efficiency though cooperation with other transporting industries. Different enterprises can con-transport goods of different enterprises by adopting same method. When the logistics scope is close by and the logistics amount in a certain time is less, it is obviously uneconomical for some enterprises carry out logistics operation in the meantime. So, the phenomenon appears that an enterprise transporting its goods with some of other enterprises.

The union of road container transport enterprises shall specify the management system inside the industry and ask all the enterprises to sign labour contract with drivers, specify the employment relationship, explicit benefits relationship and salary distribution method; take labour protection measures for the driver, take insurance and social ensure for them to ensure drivers' personal safety; specify the relationship with affiliated ones, execute contract with them to reduce labour dispute. Transport enterprises are not allowed to transfer its risk to drivers. Strengthening communication to build up a bilateral and multilateral mechanism to solve dispute and ensure social stability.

\subsection{Win-Win Strategy with the Enterprises (The Owners of the Commodities)}

With the integration of global economy, No any enterprise can be the most outstanding one in all business, all have to unite enterprises in the upper and down streams; form an industry supply chain connected economic benefits and close business relationship for complementary strengths, take the advantages of all available resource to get well with the competition environment of great socialization production, improve the competitiveness in the market. So, the internal supply chain must be extended and developed to the one for the whole industry and the resources of management from inner part to exterior part.

The road container transport enterprises have to strengthen the cooperation and communication with large-size manufacturers and makes them change their operation principles to get out from the mis-conceptions of "big and comprehensive" and "small and comprehensive", to farm out the logistics business, to establish a supply chain style management and service system of Industry segmentation, intensive resource and quick response. By cooperation to participate the competition with integrative advantages of the supply chain, to achieve mutual benefit; to look for strategic cooperation with core enterprises and become a long-term and stable strategic partner of core enterprises. 


\subsection{Coordinative Strategy with the Government}

The road container transport enterprises have to strengthen the coordination and communication with government, deal with the relationship of government and enterprise, ask local government to supervise the market and specify market behavior positively, get the support of industrial supervisor on the policy of logistics planning, land, information construction etc. and give their support and favour in funds, bank load and tax ...etc.

The key task of the government is to establish and maintain an "information service platform". This "Information service platform " is basic, public, service and functionality, the government should coordinate and push the key logistics information project, devote their major efforts to integrate projects such as the public information platform of road container transport, maritime network, logistics customs information system of Qianhaiwan tariff-free area in Shenzhen, the customs clearance project of tariff-free logistics center (type B) at Shenzhen airport, international information center project of Yantian, aviation logistics information platform of Shenzhan City, the public information platform of Qianhaiwan logistics garden, the public information platform of Sungang logistics garden to a powerful information service platform of wide coverage, to make it have the function of port certificate, identity identify, information collection, auto toll and quick customs clearance...etc. and business as container reservation, to improve its level of modernized management.

\subsection{Cooperative Strategies with International Container Wharf}

How to cooperate the road container transport enterprises with wharf to improve efficiency of entire logistics system is a critic problem need to be solved immediately.

Container-trailers have to go through the lock gate to transport the containers, information have to be inputted, documents have to be checked by drivers according the application. Because driver and trailer are integrated, the phenomenon of a long queue for waiting in wharf is very usual. This has already become the bottleneck of the pass capacity of container ports. For the trailer enterprises, the longer they waits, the greater influence will be, this also lower the service level for their customer; deduced the throughput of unclogging port as while as lower the competition ability of wharf.

To solve this problem, the port should carry out cooperation with trailer enterprises and government to establish a "information service platform". All the information of import and export containers, trailer enterprises and trailer drivers should be put into this "information service platform (system)" to build a systematic reservation service system for container-trailers.

In other words, all the information of road container transport enterprises or container-trailer drivers have to be inputted into the service system by phonetic system or network by advance. The lock gate staff have to check all the data to make sure all are completed and in effect, and feedback to trailer drivers for the time and place information for connection transport the containers, then, drivers should transport the containers according to the reserved time and place. When enter the lock gate, they should check the waiting time, they can get the CMC directly to enter the stock yard after finish the checking, shown as figure 1. 


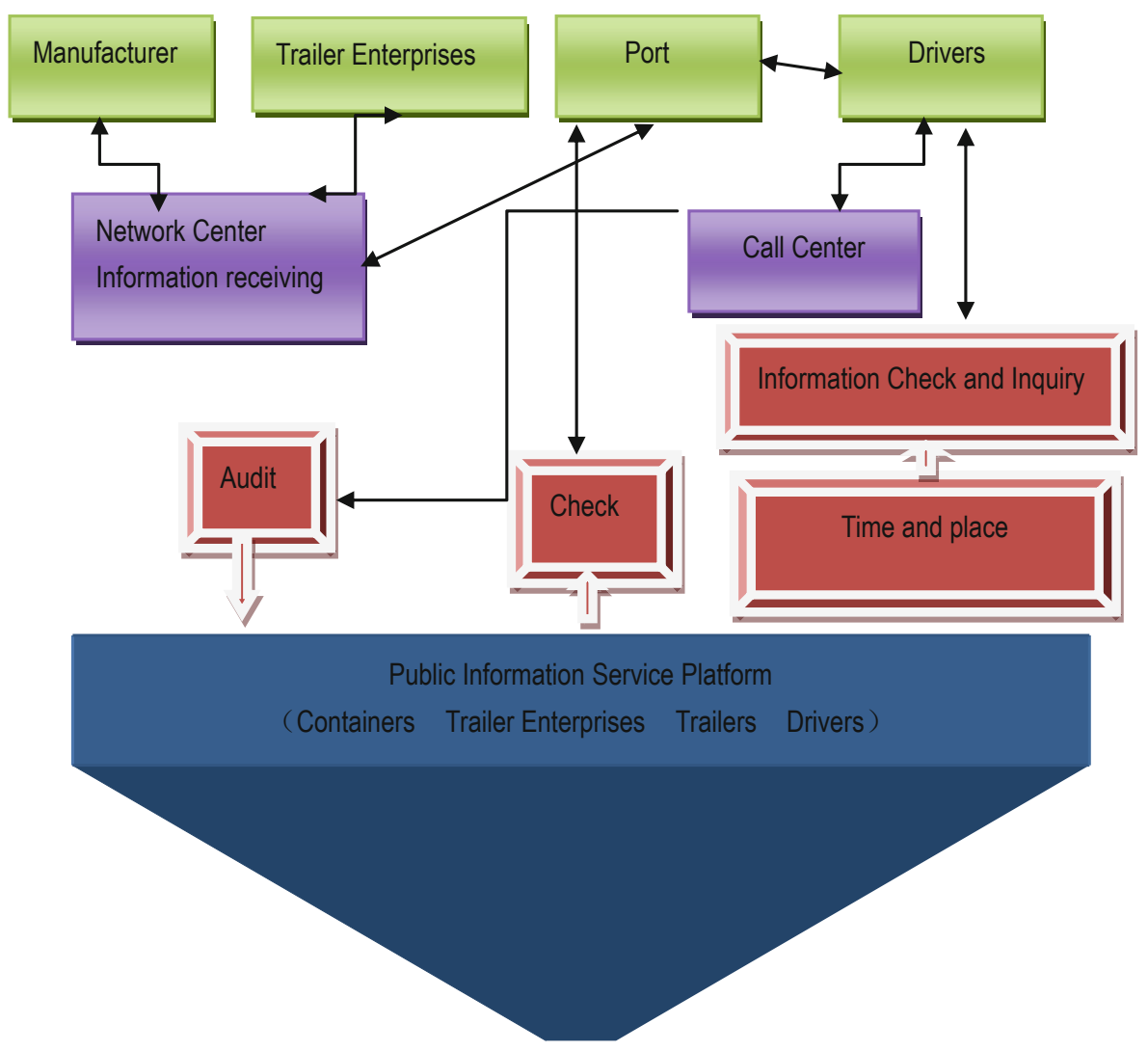

Fig. 1. Diagram of Container-Trailer Reservation System

The container trailer reservation system withdraw the customer's transport information in advance without a fixed time, this make trailer enterprises and drivers to arrange their time accordingly. It improves the cooperative abilities of related enterprises and reduces the waste, raises the mutual competition abilities of cooperative enterprises.

\section{Conclusion}

To manage the current operation problems of road container transport enterprise, the enterprise should actively develop cooperation with related enterprise and the government. Only by this way, the enterprises can get rid of current operation dilemma. And the cooperation can get away with strong information-based and network support. Without information-based technical means, the cooperation cannot go further. In the meanwhile, information construction need the support of government, only when above problem is solved, container transport enterprises then can be really get rid of current operation dilemma and support the development of local economy. 


\section{References}

[1] Yang, C., Rong, C.: Look at the Development of Shenzhen Port Though the Generatiion Development of Ports. Comprehensive Transport (01) (2009)

[2] Zhou, X. Development Situation and Strategies of Development of Road Container Transport Industry in Shenzhen City. Container Transport (01) (2009)

[3] Xiang, W., Yi, Y.: SWOT Analysis and Strategies for the Development of Modern Logistics Industry in Shenzhen. The Consumption Guider (17) (2009)

[4] Suggestion to Establish Standards for Chinese Road Container Transport Industry. Containerization (01), 20-21 (2010)

[5] Jiang, J.: A Study on key problem of transformation from traditional logistics enterprise toward modern logistics service supplier. Maritime University of Dalian (2007)

[6] Gao, N.: A Study on Improving the Lock-gate Passing Capacity of a Container Wharf in Shenzhen. Maritime University in Dalian (2008)

[7] Yang, X.: The Development Strategic Analysis of Logistics Industry in Yantian Port. Southwest Transportation University (2009)

[8] The People's Republic of China Maritime Customs Headquarters, http: / /www. customs.gov.cn/publish/portalo/

[9] The reform and development outline of Zhujiang Delta (2008-2020), the National Development and Reform Commission (2008)

[10] The Latest Statistics for 2010 of Shenzhen Transportation Bureau (Harbor Management Administration)

[11] The Eleventh 5-Year Development Plan for Modern Logistics Industry of Shenzhen [Z]Shenzhen Transportation Gureau (2007)

[12] The Website of China Container-Trailer Association, http: / /www. chinaccia.com

[13] The website of Shenzhen Container-Trailer Association, http:llwww.sztx.org.cn/

[14] International Website of Yantian, http: / / www.yict.com. cn

[15] The website of Shekou Container Wharf Limited Company, http: //www.sctcn.com/

[16] The website of Chiwan Container Wharf Limited Company, http://www.cwcct.com/Catalog_23.aspx

[17] Hesse, M., Rodrigue, J.P.: Global production networks and the role of logistics and transportation. Growth and Change 37(4), 500-510 (2006)

[18] Xie, F., Zhang, N., Ji, S.W.: Study on multi-transportation Path selection based on AHP. Logistic Technology 29, 13-17 (2006)

[19] Hertz, S., Alfredsson, M.: Strategic development of third party logistics Providers. Industrial Marketing Management 32(2), 139-149 (2003) 